\title{
Visible Spectrophotometric and Thermodynamic Studies of Diclofenac: Charge-Transfer Complexation with 2, 3 Dichloro-5, 6-dicyano, 1, 4-benzoquinone
}

\author{
Ikemefuna C Uzochukwu* and Stanley O Nzegbunam \\ Department of Pharmaceutical and Medicinal Chemistry, Faculty of Pharmaceutical Sciences, Nnamdi Azikiwe University, PMB \\ 5025, Awka 420281, Nigeria
}

*For correspondence: Email: ic.uzochukwu@unizik.edu.ng; Tel: +234 8035476925

\begin{abstract}
Purpose: To investigate the visible spectrophotometric and thermodynamic parameters of diclofenac with regard to charge-transfer complexation with 2, 3-dichloro-5, 6-dicyano-1, 4-benzoquinone.

Methods: The wavelength of maximum absorption, stoichiometry, time-absorbance relationship, effect of $\mathrm{pH}$, Beer's plot and Beer's law limit for the complex were evaluated for diclofenac. In order to validate an assay method based on the complexation reaction, the limit of detection and quantitation, precision, accuracy and selectivity were determined. The developed assay method was applied to the assay of diclofenac tablet and capsule brands.

Results: A 1:1 complex that absorbed maximally at $506 \mathrm{~nm}$ and a Beer's plot with a regression coefficient of $0.9970 \pm 0.0010$ were obtained. Beer's law was obeyed in the concentration range of 0.0017 to $0.2111 \mathrm{mg} / \mathrm{ml}$ and precision was within acceptable limits. The limits of detection and of quantitation of the method was 0.000801 and $0.002426 \mathrm{mg} / \mathrm{ml}$, respectively. The spontaneity of the complexation reaction was demonstrated by negative Gibb's free and positive entropy energy changes. The drug content of commercial diclofenac products to which the assay method was applied was between 94 and $102 \%$.

Conclusion: Charge-transfer complexation of diclofenac with 2, 3-dichloro-5, 6-dicyano-1, 4benzoquinone is straightforward, and the assay method based on it is simple and robust for the determination of diclofenac in tablet or capsule formulation.
\end{abstract}

Keywords: Spectrophotometry, Charge transfer complex, Diclofenac, Tablets, Capsules, Validation

Tropical Journal of Pharmaceutical Research is indexed by Science Citation Index (SciSearch), Scopus, International Pharmaceutical Abstract, Chemical Abstracts, Embase, Index Copernicus, EBSCO, African Index Medicus, JournalSeek, Journal Citation Reports/Science Edition, Directory of Open Access Journals (DOAJ), African Journal Online, Bioline International, Open-J-Gate and Pharmacy Abstracts

\section{INTRODUCTION}

Diclofenac sodium, 2-[2, (6-dichlorophenyl)amino] benzene acetic acid monosodium salt, is a non-steroidal anti-inflammatory drug with potent activity and outstanding tolerability, and is used as an analgesic, antipyretic and antiinflammatory agent [1].

Formulations of diclofenac have been assessed by ultraviolet spectrophotometry [2,3], spectrofluorimetry [4], flow extraction spectrophotometry [5], Raman spectroscopy [6], and gas-liquid chromatography for biological fluids [7-9]. Molecular spectroscopic methods based upon the formation of ion-pairs [10-12] have also been reported. Non-aqueous titration with perchloric acid and reversed phase HPLC method are recommended in the British Pharmacopeia for diclofenac pure form and tablets respectively [13]. 
HPLC methods have suffered from such challenges as long analysis time, large consumption of solvents and reagents, high cost, complicated routine maintenance, ease of use and large dimension [14]. Simple, cheap and accurate assay methods are desirable for routine quality control of pharmaceuticals, especially in resource-poor countries. Spectrophotometry is the most widely used technique in pharmaceutical analysis because of its inherent simplicity and wide availability in most quality control laboratories [15].

Literature survey revealed that charge transfer complexation of diclofenac with 2, 3-dichloro-5, 6-dicyano-1,4- benzoquinone (DDQ) has not been investigated. The rapid formation of intensely colored charge-transfer complexes has led to the use of $\pi$ - acceptors such as DDQ in the development of visible spectrophotometric methods for analysis of many pharmaceutical compounds [16]. Since the alkali salts of carboxylic pharmaceutical compounds have been demonstrated to have excellent electrondonating ability [17], we anticipated same for diclofenac sodium. The study investigated the charge-transfer complexation of diclofenac sodium with 2, 3-dichloro-5, 6-dicyano-1, 4benzoquinone. The thermodynamic parameters of the formed complex were also determined.

\section{EXPERIMENTAL}

\section{Reagents and apparatus}

Pure diclofenac sodium was a gift from Healthy Life Pharma, India. Diclofenac tablets and capsules were obtained from pharmacy shops and open market in Onitsha, Nigeria. Analytical grade of DDQ (Merck, Germany) and methanol (BDH, England) were used for the experiments. All absorption measurements were made on a computerized double-beam ultraviolet/visible Jenway 6505 spectrophotometer with matched 1 $\mathrm{cm}$ quartz cuvette. Ohaus analytical balance (PA214), $10 \mathrm{ml}$ pipettes, test tubes, measuring cylinder, beakers, glass funnels, $100 \mathrm{~mL}$ volumetric flask were also used in the experiments.

\section{Preparation of reagents}

A $100 \mathrm{mg}$ of DDQ was accurately weighed using a Jenway analytical balance, dissolved with small volume of absolute methanol and made up to $100 \mathrm{ml}$ mark with the same solvent in a volumetric flask $(1 \mathrm{mg} / \mathrm{ml})$. A $22.7 \mathrm{ml}$ of stock solution was diluted with $27.3 \mathrm{ml}$ of absolute methanol to obtain a $0.002 \mathrm{M} \mathrm{DDQ}$ solution.
To prepare a $0.002 \mathrm{M}$ diclofenac sodium solution, $63.626 \mathrm{mg}$ of diclofenac sodium was accurately weighed, dissolved with small volume of absolute methanol and made up to $100 \mathrm{ml}$ mark with the same solvent in a volumetric flask $(0.63626 \mathrm{mg} / \mathrm{ml})$.

\section{Wavelength of maximum absorption}

A $2 \mathrm{ml}$ diclofenac solution in methanol $(0.002 \mathrm{M})$ was mixed with $2 \mathrm{ml}$ of DDQ $(0.002 \mathrm{M})$ and scanned between 200 and $800 \mathrm{~nm}$ wavelength at $1 \mathrm{~nm}$ interval against a methanol solvent blank using Jenway 6505 computerized UV/Visible spectrophotometer. Similarly, diclofenac sodium $(4 \mathrm{ml})$ and DDQ (4 ml) solutions in methanol were each also scanned spectrophometrically in the wavelength range of $250-400 \mathrm{~nm}$ wavelength against methanol solvent blank. Wavelengths of maximum absorption were determined from the scan results.

\section{Stoichiometric ratio}

The Job's method of continuous variation was employed [21]. Master equimolar solutions $(2 \times$ $10^{-3} \mathrm{M}$ ) of each of diclofenac and DDQ were prepared. Series of $10 \mathrm{ml}$ portions of the master solutions of diclofenac with DDQ were made up comprising different complementary ratios $(0: 10$, 1:9, 9:1 and 10:0) in each of the test tubes. The reaction was allowed to proceed at room temperature $\left(32 \pm 1{ }^{\circ} \mathrm{C}\right)$ for $5 \mathrm{~min}$. The absorbance values (in triplicate) of the different ratios were measured at $506 \mathrm{~nm}$ wavelength against blank cells treated similarly except methanol was used instead of diclofenac sample. The absorbance values were plotted as a function of diclofenac mole fraction. The molar ratio of diclofenac: DDQ was determined as the point of inflection in the curve.

\section{Time-absorbance relationship}

Freshly prepared diclofenac solution $(0.002 \mathrm{M})$ was complexed with equal volume of freshly prepared DDQ $(0.002 \mathrm{M})$ solution. The absorbance values of the mixtures were determined at $506 \mathrm{~nm}$ wavelength at intervals $(0$, $2,5,10,15,20,30,40,50,60,80,100$ mins, 2 , $3,5,7,12$ and $24 \mathrm{~h}$ ) using the UV/Visible spectrophotometer.

\section{Effect of pH on complex formation}

Buffer solutions ( $\mathrm{pH} \mathrm{1,} \mathrm{3,} \mathrm{5,} \mathrm{7,} \mathrm{9,} 11$ and 13) were prepared. A $2 \mathrm{ml}$ each of diclofenac solution $(0.002 \mathrm{M})$ and $\mathrm{DDQ}$ solution $(0.002 \mathrm{M})$ were mixed with $6 \mathrm{ml}$ of the buffer solution. The 
absorbance values of the resulting complexes were determined at $506 \mathrm{~nm}$ wavelength using the UV/Visible spectrophotometer. A graphical plot of the absorbance values against the $\mathrm{pH}$ was drawn using Microsoft Excel $\circledR$ tool pack. The optimum $\mathrm{pH}$ range for complexation was determined from the graph plot.

\section{Determination of linearity}

A $1.2 \mathrm{ml}$ of diclofenac sodium stock solution (2.0 $\times 10^{-3} \mathrm{M}$ ) was complexed with $1.2 \mathrm{ml}$ stock of $\operatorname{DDQ}\left(2.0 \times 10^{-3} \mathrm{M}\right)$ and the volume made up to 6 $\mathrm{ml}$ with methanol affording a $21.11 \mathrm{mg} \%$. Serial dilutions were made to afford $0.17-21.11 \mathrm{mg} \%$. The absorbance values of the serial dilutions were determined after $60 \mathrm{~min}$ at $506 \mathrm{~nm}$ wavelength against methanol blank spectrophotometrically. A graphical plot of the absorbance values against the concentration afforded a calibration curve. The slope and correlation coefficient of the linear plot were extracted from the graph.

\section{Evaluation of Beer's law limit}

Concentrations of $0.002 \mathrm{M}$ diclofenac sodium solution $(0.00001,0.0001,0.001,0.01,0.1,10$, $20,40,60,80,100,120 \mathrm{mg} \%$ ) were mixed with equal volumes of $0.002 \mathrm{M} \mathrm{DDQ}$. The absorbance values of the formed complexes were determined after $60 \mathrm{~min}$ at $506 \mathrm{~nm}$ wavelength against the methanol solvent blank. A graphical plot of the absorbance values against concentration afforded a curve from which the Beer's limit was estimated.

\section{Molar absorptivity, association constants and thermodynamic parameters}

Serial volumes $(0.4,0.8 \ldots \ldots 2.4 \mathrm{ml})$ of a $0.002 \mathrm{M}$ diclofenac solution were placed in different test tubes, diluted to $3 \mathrm{ml}$ with methanol and each reacted with serial volumes $(0.4,0.8 \ldots \ldots .2 .4 \mathrm{ml})$ of $0.002 \mathrm{M}$ DDQ solution. The contents were mixed, left at room temperature for $60 \mathrm{~min}$ and their absorbance values determined at $506 \mathrm{~nm}$ wavelength against a blank prepared simultaneously without diclofenac. Similarly, diclofenac and DDQ were reacted in a water bath at temperatures of $40,50,60$ and $70{ }^{\circ} \mathrm{C}$ respectively. The molar absorptivity and association constant of the complexes obtained at different temperatures were calculated using Benesi-Hildebrand equation as in Eq 1 [18].

$\left[D_{0}\right]\left[A_{\circ}\right] / A^{A D}=\left\{\left[D_{0}\right] / \varepsilon^{A D}\right\}+\left\{1 /\left[K^{A D} \varepsilon^{A D}\right]\right\}$

where $\left[D_{0}\right]$ and $\left[A_{0}\right]$ are the initial concentration of the reactant species, $A^{A D}$ is the absorbance of the complex, $\varepsilon^{A D}$ is the molar absorptivity and $\mathrm{K}^{\mathrm{AD}}$ is the association constant.

A graphical plot of $\left[D_{0}\right]\left[A_{0}\right] / A^{A D}$ versus $\left[D_{0}\right]$ affords a straight line whose slope is equal to $1 / \varepsilon^{A D}$ and intercept is $1 /\left[K^{A D} \varepsilon^{A D}\right]$.

The standard enthalpy change, $\Delta \mathrm{H}^{\circ}$, of the interaction was calculated from the slope of the graphical plot of log $\mathrm{K}$ versus $1 / \mathrm{T}$. The Gibbs free energy, $\Delta G^{\circ}$, for the respective complexes were obtained from Eq 2.

$\Delta G^{\circ}=-R T \ln K^{A D}$

Consequently, the entropy, $\Delta S^{\circ}$, for the respective complexes were computed from Eq 3.

$\Delta \mathrm{G}^{\circ}=\Delta \mathrm{H}^{\circ}-\mathrm{T} \Delta \mathrm{S}^{\circ}$

\section{Assay of diclofenac tablets and capsule}

Twenty tablets of each brand of diclofenac were individually weighed and the average weight for each brand calculated. Twenty tablets were powdered and the powdered sample equivalent to $100 \mathrm{mg}$ of diclofenac sodium was transferred to $100 \mathrm{ml}$ volumetric flask, made up to $100 \mathrm{ml}$ volume with the methanol (100 $\mathrm{mg} \%)$, vigorously shaken and filtered. The filtrate was thereafter made up to $100 \mathrm{ml}$ with methanol. The filtrate $(0.8 \mathrm{ml})$ was complexed with $0.8 \mathrm{ml}$ of DDQ solution $\left(2.0 \times 10^{-2} \mathrm{M}\right)$ in a test tube and the volume made up to $6 \mathrm{ml}$ with methanol. The complexation was allowed to proceed for $60 \mathrm{~min}$ at room temperature and the absorbance value determined at $506 \mathrm{~nm}$ wavelength against a blank of methanol using the UV/Visible spectrophotometer. The assay of each brand was repeated thrice. Content of diclofenac sodium in each brand was estimated from the calibration curve of the diclofenac complex.

\section{Detection limits}

The limit of detection (LOD) and of quantitation (LOQ) were determined using the formula: LOD or $L O Q=\kappa S D a / b$, where $k=3$ for LOD and 10 for LOQ, SDa is the standard deviation and $b$ is the slope of the calibration curves of the complex [19].

\section{Accuracy}

Accuracy of the proposed assay was assessed by recovery experiments using the standard addition method. Two different samples of $20 \mathrm{mg}$ $\%$ of diclofenac complex were prepared and placed in a $100 \mathrm{ml}$ volumetric flask. Two concentration (5 and $10 \mathrm{mg} \%$ ) of pure diclofenac 
sodium complex were prepared and respectively added to the $20 \mathrm{mg} \%$ complex, to afford 25 and $30 \mathrm{mg} \%$ respectively. The mixtures were vigorously shaken and made up to $100 \mathrm{ml}$ mark. The mixture $(2 \mathrm{ml})$ was diluted with methanol to the $100 \mathrm{ml}$ mark in a volumetric flask and the absorbance determined spectrophotometrically at $506 \mathrm{~nm}$ against methanol as blank, and percent recovery computed.

\section{Intra-day and inter-day precision}

Intra-day precision of the method was investigated by obtaining duplicate absorbance readings of ten different aliquots of a $2 \mathrm{mg} \%$ diclofenac complexed with $2 \mathrm{mg} \%$ DDQ at 506 $\mathrm{nm}$ wavelength using UVNisible spectrophotometer. The results were computed as in Eq 4.

$\mathrm{X}_{1}-\mathrm{X}_{2} /\left(\mathrm{X}_{1}+\mathrm{X}_{2}\right) / 2$

where $X_{1}$ and $X_{2}$ are the duplicate results from individual samples.

The inter-day precision of the method was evaluated by analyzing the absorbance values of a freshly complexed $2 \mathrm{mg} \%$ of diclofenac in methanol with $2 \mathrm{mg} \% \mathrm{DDQ}$ daily for five days. Duplicate absorbance readings of samples were obtained at $506 \mathrm{~nm}$ wavelength using UV/Visible spectrophotometer and investigated using the formula,

$\mathrm{X}_{1}-\mathrm{X}_{2} /\left(\mathrm{X}_{1}+\mathrm{X}_{2}\right) / 2$

where $\mathrm{X}_{1}$ and $\mathrm{X}_{2}$ are the duplicate results from individual samples.

\section{Selectivity}

Various tablet excipients, lactose and starch (singly or mixed in different proportions), were mixed with freshly formed diclofenac complex respectively and their absorbance determined spectrophotometrically at $506 \mathrm{~nm}$ The results were compared with those for complexes without excipients.

\section{Statistical analysis}

The results are expressed as mean \pm standard error of mean (SEM) or as percentages, where applicable. Microsoft Excel® 2010 package was used for the analysis.

\section{RESULTS}

The result of the optical characteristics of diclofenac sodium complexed with DDQ is shown in Table 1.

A 1:1 stoichiometric complex was formed between diclofenac sodium and DDQ as seen in the Job's plot (Fig 1).

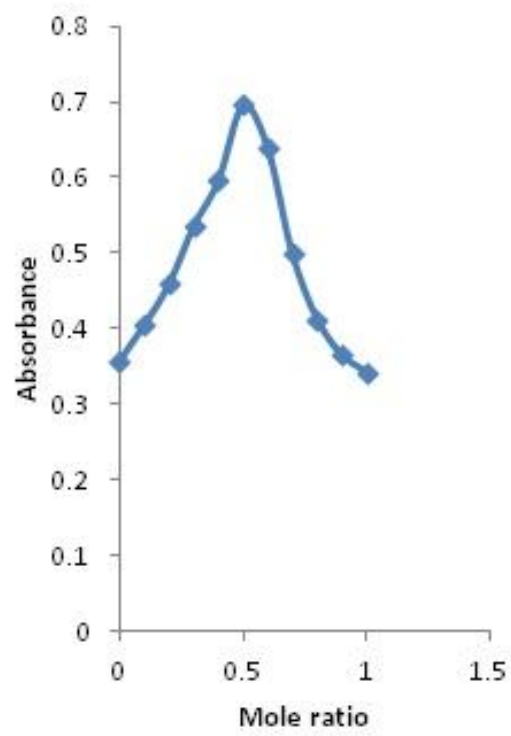

Figure 1: Job's plot for charge-transfer reaction of diclofenac with $\mathrm{DDQ}$

Table 1: Optical characteristics of diclofenac: DDQ complex in absolute methanol

\begin{tabular}{lc}
\hline Parameter & Value \\
\hline Wavelength & $506 \mathrm{~nm}$ \\
Slope & 0.023 \\
Beer's law limits & 0.0017 to $0.2111 \mathrm{mg} / \mathrm{ml}$ \\
Regression equation & $\mathrm{y}=0.0235 \mathrm{x}$ \\
Correlation coefficient & $0.9977 \pm 0.0010$ \\
Limit of detection & $0.000801 \mathrm{mg} / \mathrm{ml}$ \\
Limit of quantitation & $0.002426 \mathrm{mg} / \mathrm{ml}$ \\
Percentage recoveries & 99.54 to $100.14 \%$ \\
Inter-day precision (relative range) & 0.0000 to 0.00163 \\
Intra-day precision (relative range) & 0.0000 to 0.00192 \\
\hline
\end{tabular}


The investigation into the time-absorbance relationship of the diclofenac sodium and DDQ complex showed that even though the complex formation was spontaneous, no less than $60 \mathrm{~min}$ was required for the complexation reaction to come to completion. The formed complex was also found to be stable for over $24 \mathrm{~h}$. The $\mathrm{pH}$ studies showed that the diclofenac: $\mathrm{DDQ}$ complex was favoured in the acidic region $(\mathrm{pH}, 1$ - 6). The $\mathrm{pH}$ of unbuffered complex was found to be 5.8. Beer's plot for the diclofenac sodium and DDQ complex afforded a linear graph with high regression coefficient of 0.9977 as reported in Table 1.

Good recovery results (> $99 \%$ ) were obtained from the selectivity experiments. Molar absorptivity and standard enthalpy change $\left(\Delta \mathrm{H}^{\circ}\right)$ of diclofenac: DDQ complex were 0.01 and $61.85 \mathrm{kcal} / \mathrm{deg} / \mathrm{mol}$, respectively, at all the tested temperatures (303 to $343 \mathrm{~K})$. Association constants of 220.0, 209.8, 206.0, 183.0 and 174.6 were found for the diclofenac: DDQ complexes at $303,313,323,333$ and $343 \mathrm{~K}$, respectively. Gibbs free energy change $\left(\Delta G^{\circ}\right)$ and entropy change $\left(\Delta S^{\circ}\right)$ for the respective complexes ranged from -103.29 to -98.86 and 0.14938 to $0.09673 \mathrm{kcal} / \mathrm{deg} / \mathrm{mol}$ respectively.

The results of the identity profile and the assay of diclofenac brands using the proposed assay method are shown in Table 2 below.

\section{DISCUSSION}

The result of the optical characteristics of diclofenac sodium complexed with $\mathrm{DDQ}$ as shown in Table 1 above confirms the formation of a charge transfer complex between diclofenac sodium and DDQ in methanol. Whereas diclofenac sodium in methanol itself shows maximum absorption at $357 \mathrm{~nm}$ wavelength, it was found to spontaneously form a blood-red complex with DDQ absorbing at $506 \mathrm{~nm}$ wavelength (visible region) of the electromagnetic region. The formation of a blood-red colour on reaction of the yellow coloured DDQ solution and the colourless diclofenac sodium solution in methanol was suggestive of a charge transfer complex formation. This charge transfer complexation may be attributed to one or more of the three lone pairs electrons present in the drug molecule. It is thought that the carboxylate group of diclofenac contributed lone pairs of electrons which could extend the aromatic conjugation of diclofenac. These lone pairs of electrons are thought to have been donated to DDQ leading to the charge transfer complex formation evidenced by the bathochromic shift ( 357 to $506 \mathrm{~nm}$ ).

The stoichiometry of complex formation between diclofenac and DDQ was investigated using the Job's method of continuous variation [18]. The result obtained is indicative of a strong electron donating center in the molecular structure of diclofenac sodium. The result obtained (1:1) also guided the choice of reacting ratio between diclofenac sodium and DDQ.

Absorbance values obtained from complexation products may be variable if complexation is incomplete or the complex is unstable. In order to reduce this variability, we examined the timeabsorbance relationship of the formed complex. The result showed that complete complexation, which occurred from the sixtieth minute, was a necessary condition for absorbance measurements. Once the complex was completely formed, it remained stable for as long as $24 \mathrm{~h}$. The implication of the long stability of the formed complex is that the proposed assay method will allow the analyst enough time for

Table 2: Drug content of diclofenac product brands (labelled strength, $400 \mathrm{mg}$ )

\begin{tabular}{|c|c|c|c|c|c|c|c|}
\hline $\begin{array}{l}\text { Brand } \\
\text { Codel } \\
\text { Dosage } \\
\text { form }\end{array}$ & $\begin{array}{l}\text { Country } \\
\text { of origin }\end{array}$ & $\begin{array}{l}\text { NAFDAC } \\
\text { Reg. } \\
\text { Number }\end{array}$ & Lot no. & $\begin{array}{l}\text { Manufacture } \\
\text { date }\end{array}$ & $\begin{array}{l}\text { Expiry } \\
\text { date }\end{array}$ & $\begin{array}{c}\text { Mean } \\
\text { weight } \pm \\
\text { SEM }(\mathrm{mg})\end{array}$ & $\begin{array}{c}\text { Absolute } \\
\text { drug } \\
\text { content } \\
(\%)\end{array}$ \\
\hline $\begin{array}{l}(\mathrm{A}) / \\
\text { Tablet }\end{array}$ & England & 04-7290G & 0901140 & Jan 2011 & Jan 2014 & $\begin{array}{c}0.2203 \\
\pm 0.0001\end{array}$ & 94.48 \\
\hline $\begin{array}{l}\text { (B) / } \\
\text { Tablet }\end{array}$ & India & R1392 & SR003 & Feb 2011 & Jan 2014 & $\begin{array}{c}0.1977 \\
\pm 0.0001\end{array}$ & 94.04 \\
\hline $\begin{array}{l}\text { (C) / } \\
\text { Tablet }\end{array}$ & Malaysia & 04-9497 & BB02557 & Feb 2011 & Feb 2014 & $\begin{array}{c}0.2249 \\
\pm 0.0001\end{array}$ & 100.44 \\
\hline $\begin{array}{l}\text { (D) / } \\
\text { Tablet }\end{array}$ & Israel & 04-0928 & 1106174 & Jun 2011 & June 2014 & $\begin{array}{c}0.2138 \\
\pm 0.0001\end{array}$ & 97.76 \\
\hline $\begin{array}{l}\text { (E) / } \\
\text { Capsule }\end{array}$ & Nigeria & A4-3528 & 1140501 & May 2011 & April 2014 & $\begin{array}{r}0.2915 \\
\pm 0.0001\end{array}$ & 102.34 \\
\hline
\end{tabular}


analysis and that the proposed complexation method is a robust assay method.

The investigation into the effect of $\mathrm{pH}$ on the diclofenac: DDQ complex formation showed that the use of a buffer system for optimum complexation of diclofenac sodium with $\mathrm{DDQ}$ was unnecessary. The $\mathrm{pH}$ of unbuffered complex $(\mathrm{pH}, 5.8)$ coincided with the optimum $\mathrm{pH}$ range $(\mathrm{pH}, 1-6)$ for complexation. It was deduced that the assay method developed from the complexation reaction may be minimally affected by the sample matrix.

Our results showed that Beer's law (linearity between concentration and absorbance) was obeyed by the formed complex in dilute solutions and that linearity was lost at high concentrations. This is consistent with the observation that absorbing species usually deviate from the Beer's law at high concentrations. The high regression coefficient of 0.9977 was indicative of high linearity between the concentration of the complex and the absorbance values. This indicates that the proposed assay method is suitable for the intended assay.

In order to understand the influence of tablet or capsule excipients on the accuracy of the proposed method, the selectivity experiments were done with lactose and starch. Lactose and starch are commonly used tablet excipients which may influence assay of active ingredients in formulations containing them. The investigation into the selectivity of the proposed complexation method showed minimal interference on the absorbance values of the complex as a result of the lactose and starch excipients added to the diclofenac and DDQ complexation matrix. This was inferred from the high percentage recoveries obtained in the experiment.

The values (Table 1) obtained for the LOD, LOQ, percent recoveries, intra-day and inter-day precisions were considered acceptable for the intended assay. The near ten-fold difference between the LOD and LOQ is an indication of the high sensitivity of the proposed complexation assay method. Near $100 \%$ recovery values confirmed the accuracy of the proposed assay method. Minimal relative changes as obtained from intra-day and inter-day precision experiments show that the proposed assay method would be robust for the intended application.

The negative Gibbs free energy change $\left(\Delta G^{\circ}\right)$ and positive entropy change $\left(\Delta S^{\circ}\right)$ obtained for diclofenac: $D D Q$ complexes are consistent with expected thermodynamic parameters for a spontaneous reaction. Both $\Delta \mathrm{G}^{\circ}$ and $\Delta \mathrm{S}^{\circ}$ were dependent on temperatures of complexation. While $\Delta G^{\circ}$ increased with increasing temperature, $\Delta S^{\circ}$ decreased with increasing temperature, suggesting decreased spontaneity as temperatures of complexation are elevated. The molar absorptivity and $\Delta S^{\circ}$ were found to be constant and independent of temperatures of complexation. Results obtained from the assay of commercial samples of diclofenac tablets and capsule brands further confirm the practicality of the proposed assay method.

\section{CONCLUSION}

Charge-transfer complexation of diclofenac with 2, 3-dichloro-5, 6-dicyano-1, 4-benzoquinone provides a suitable, simple and robust method for the assay of diclofenac in tablet and capsule formulations.

\section{ACKNOWLEDGEMENT}

The authors acknowledge the contribution of $\mathrm{Dr}$ FBC Okoye to the execution of this work by providing a sample of DDQ from Merck, Germany.

\section{REFERENCES}

1. Reynolds JEF. Martindale, The Extra Pharmacopoeia, 28th edn, The Pharmaceutical Press. London; 1990; p 36 .

2. Vaidya $R$, Prasad RS. Spectrophotometric determination of diclofenac diethylammonium and its dosage forms. Indian Drugs 1995; 32: 194-196.

3. Mo, Z, Chen Z. UV spectrophotometric determination of compound diclofenac sodium injection. Yaowu Fenxi Zazhi 1988; 8: 314-316.

4. Carreria LA, Rizk M, El-Sabrawy, Zakhari NA, Toubar SS. Europium (III) ion probe spectrofluorometric determination of diclofenac sodium. J Pharm Biomed Anal 1995; 13: 1331-1337.

5. Perez-Ruiz T, Martinez-Lozano C, Sanz A, Miguel MTS. Flow extraction spectrophotometric method for the determination of diclofenac sodium in pharmaceutical preparations. J Pharm Biomed Anal 1997; 16: 249254.

6. Davies MC, Binns JS, Melia CD, Hendra PJ, Bourgeois $D$, Church SP, Stephenson PJ. FT Raman spectroscopy of drugs in polymers. Int J Pharm 1990; 66: 223-232.

7. De-Jong EG, Kiffers J, Maes RAA. The determination of non-steroidal anti-inflammatory drugs by GC-MS-MS. J Pharm Biomed Anal 1989; 7: 1617-1622.

8. Abdel-Hamid ME, Novotny L, Hamza Hoda. Determination of diclofenac sodium, flufenamic acid, 
indomethacin and ketoprofen by LC-APCI-MS. J Pharm Biomed Anal 2001; 24: 587-594.

9. Bakkali A, Corta E, Berrueta LA, Gallo B, Vicente $F$. Study of the solid-phase extraction of diclofenac sodium, indomethacin, and phenylbutazone for their analysis in human urine by liquid chromatography. $J$ Chromatogr B 1999; 729: 139-145.

10. Agrawal YK, Shivramchandra K. Spectrophotometric of diclofenac sodium in tablets. $J$ Pharm Biomed Anal 1991; 9: 97-100.

11. Botello JC, Perez-Caballero. Spectrophotometric determination of diclofenac sodium with methylene blue. Talanta 1995; 42: 105-108.

12. Sastry CSP, Tipirneni ASRP, Suryanarayana MV. Extractive spectrophotometric determination of some anti-inflammatory agents with methylene violet. Analyst 1989; 114: 513-515.

13. British Pharmacopoeia. British Pharmacopoeia Commission, Her Majesty's Stationery Office; London, England. Vol v. 2011. pp A326 (Appendix XII C) - A327 (Appendix XX C).

14. Idris $A M$, Elgorashe RE. Sequential injection chromatography with multi-wavelength detection for separation and quantitation of propranolol and hydrochlorothiazide. Chemistry Central Journal 2011; 5: 28-51.

15. Darwish IA, Abdine HH, Amer SM, Al-Rayes LI. Spectrophotometric study for the reaction between fluvoxamine and 1,2-naphthoquinone-4-sulphonate: Kinetic, mechanism and use for determination of fluvoxamine in its dosage forms. Spectrochim Acta A Mol Biomol Spectrosc 2009; 72: 897-902.

16. Zayeda MA, Khalilb SM, El-qudabyb HM. Spectrophotometric study of the reaction mechanism between DDQ Pi- and iodine sigma-acceptors and chloroquine and pyrimethamine drugs and their determination in pure and in dosage forms. Spectrochim Acta A Mol Biomol Spectrosc 2005 Nov; 62(1-3):461-465.

17. Darwish IA. Analytical study for the charge transfer complexes of losartan potassium. Anal Chim Acta 2005; 549: 212-220.

18. Benesi H, Hildebrand JA. Spectrophotometric investigation of the interaction of iodine with aromatic hydrocarbons. J Am Chem Soc 1949; 71(Pt 8): 27032707.

19. European Medicines Evaluation Agency. Note for Guidance on Validation of Analytical Procedures: Text and Methodology, London, UK: 2006; pp 1-15. 